\title{
SEDIMENT DYNAMICS IN LAGOS HARBOUR RECONNAISSANCE ON EFFECTS OF DREDGING
}

\author{
T. Vijverberg ${ }^{1}$, M.J.J. Reneerkens ${ }^{2}$, J.C. Winterwerp ${ }^{3}$, O. Scholl ${ }^{1}$ and Y. Haruna ${ }^{4}$
}

\begin{abstract}
Due to economic growth, Lagos Harbour is expanding. Capital dredging is needed to allow larger vessels to call the port. As harbour siltation is already a problem, increase of maintenance dredging is a worry. In the past no data was available to understand the hydraulics and sediment transport to estimate maintenance dredging volumes. This paper presents the reconnaissance of the sediment dynamics in the harbour, based on field data and MIKE21 model simulations. Measurements of sediment concentration, salinity and flow velocity show that estuarine circulation occurs, transporting sediment from the ocean into the port. However, more upstream in the Commodore channel, at the location where dredging will be carried out, this circulation is small. Model simulations show that at that location, bed shear stresses are large, also after dredging. Therefore, fine sediment can not accumulate in the deepened areas and this will not result in large dredging volumes. Sand transport however can cause sedimentation, as bed forms can migrate. These mechanisms are also observed in initial sand transport simulations, but need to be studied further to fully understand the sediment dynamics in the harbour.
\end{abstract}

Keywords: Lagos Harbour; Field measurements; MIKE21 model; Sediment dynamics; Dredging

\section{INTRODUCTION}

Lagos is one of the larger cities in Africa, with a population of more than 15 million. Its harbour is important for import and export of products for the country. Since some time, more and increasingly larger vessels are calling at the port. To cope with this development, Lagos Harbour has a constant need to maintain and/or increase its navigational depths. Also new berth locations (jetties) are planned in the northern part of the Harbour, along Apapa Channel. To allow vessels to berth at the present and future jetties, capital and maintenance dredging is needed. One worry is that maintenance dredging may significantly increase due to channel deepening, as siltation problems are already a major issue in the port's area. Proper estimates of (maintenance) dredging volumes are of great importance for proper port management.

Lagos Harbour is part of an extensive estuarine system (Fig. 1 and Fig. 6). The main Harbour entrance and navigation channel connects to a large lagoon and numerous tidal creeks. The Lagos Lagoon has a surface area of approximately $200 \mathrm{~km}^{2}$, which makes it one of the bigger lagoons of the West African coast. The largest river debouching in the lagoon is the Ogun River. In the dry season (from October to May) the river discharge is of minor importance, but in the wet season (from June to September) the river can have a significant discharge. The Commodore Channel is the only significant connection between the Lagos Lagoon and the Atlantic Ocean. The large difference in precipitation between the wet and the dry season causes a significant seasonality in the discharge through the channel (Van Bentum, 2012).

The main part of Lagos Harbour is located at Apapa. At Tin Can Island also a part of the harbour is located. At the eastern tip of Snake Island several harbour and shipping activities take place. The Badagry Creek connects the harbour to the Commodore Channel. The Five Cowries Creek is a water connection between the Lagos Lagoon and the Commodore Channel (Van Bentum, 2012).

Thorough understanding of the hydraulics and sediment dynamics in the harbour area is a prerequisite for accurate estimates of dredging volumes and morphological effects caused by port developments, such as channel deepening. Due to the lack of reliable (field) data, this understanding was not present in the past. This paper addresses a reconnaissance of the sediment dynamics and the effects of local channel deepening in the Apapa area, based on data from field surveys and 2D hydrodynamic model simulations.

\footnotetext{
${ }^{1}$ Royal HaskoningDHV, PO Box 151, 6500 AD, Nijmegen, The Netherlands, (thomas.vijverberg@rhdhv.com, telephone: +31243284040)

${ }^{2}$ Aqua Vision B.V., Servaasbolwerk 11, 3512 NK, Utrecht, The Netherlands, (m.reneerkens@aquavision.nl)

${ }^{3}$ Delft University of Technology, Department of Fluid Mechanics, Stevinweg 1, 2628 CD, Delft, The Netherlands (J.C.Winterwerp@tudelft.nl)

${ }^{4}$ Nigerian Port Authority, Lagos Nigeria
} 


\section{FIELD MEASUREMENTS}

Three field measurements campaigns were carried out in August 2008, September 2010 and March/April 2011. These measurements were set up to understand the physical system and determine the main sediment transport processes in relation to dredging activities in the port. Besides, the data was used to set up a hydrodynamic model of Lagos Harbour. The model is used to determine the effects of the port developments and derive design conditions for marine structures. During the field campaigns, several parameters were measured, such as: bed levels (bathymetry), water levels, discharge, turbidity and salinity. Sediment samples were taken to determine the bed composition.

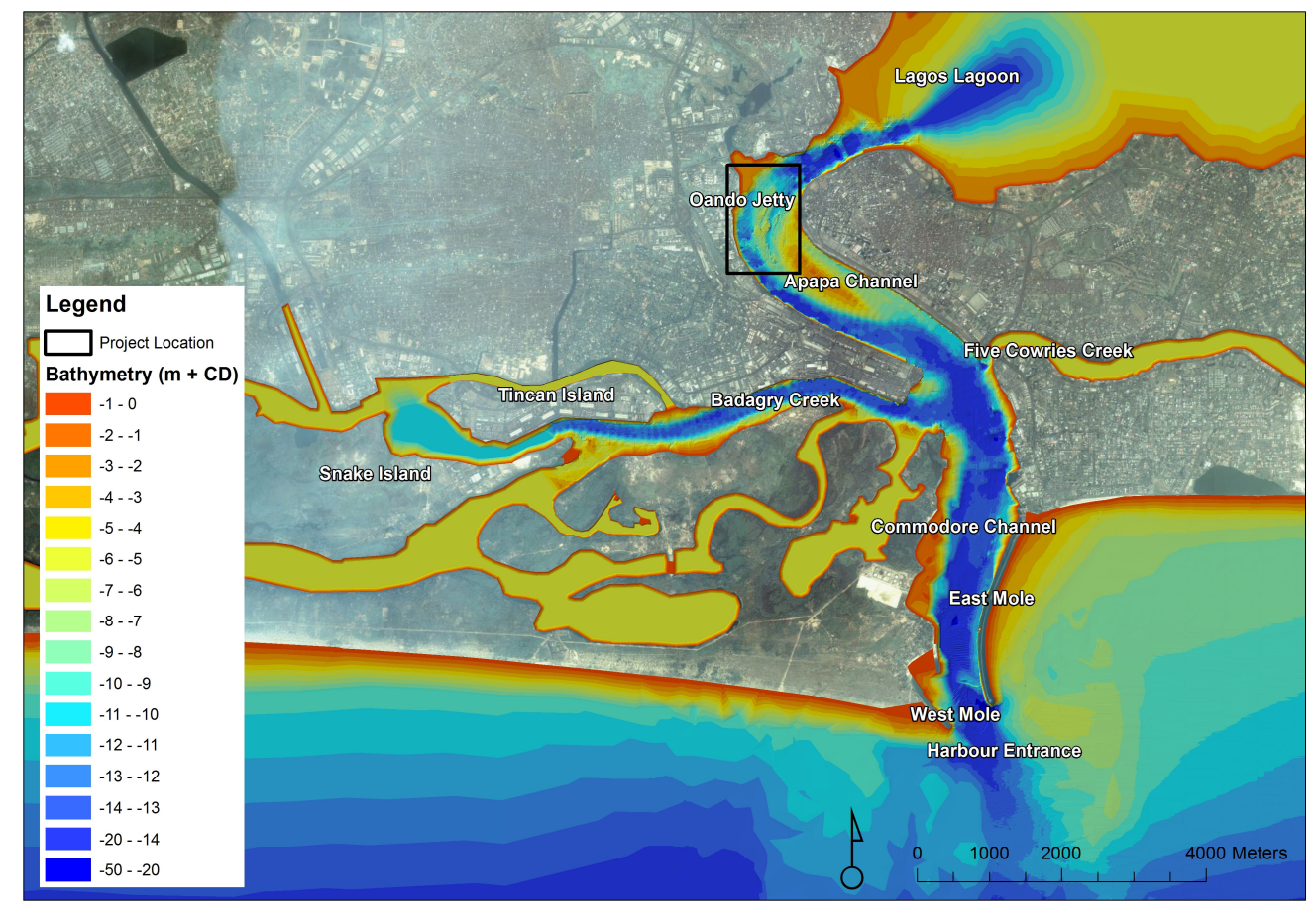

Figure 1. Overview of Lagos Harbour and its bathymetry, including locations of field measurements. Black box indicates the project location and detail of figure $2 a$ (location of capital dredging).

\section{Bathymetry}

In 2010, bed levels were measured along Commodore Channel, Apapa Channel and Badagry Creek with a dual frequency echo sounder (type: Odom Single Beam) operating at 33 and $210 \mathrm{kHz}$. Fig. 2b shows the measured area, as well as an indication of the thickness of the soft mud layer, defined as the difference between the high and low frequency echo sounder bed levels. Typical soft mud layer thickness values range from $10-30 \mathrm{~cm}$. Thicker layers are located at the connections of the Badagry Creek with the Commodore Channel $(50 \mathrm{~cm}$ to $1 \mathrm{~m}$ ) and south of Tin Can Island (up to $1 \mathrm{~m}$ or more). Along the quays in the Badagry Creek a thin soft mud layer is measured. From visual observations it is concluded that this is an area where dredging is carried out frequently. This might indicate that this is a sedimentation area and that muddy sediment must be removed frequently to guarantee enough depth for vessels. The quays along the Apapa channel show an average soft mud layer $(20-30 \mathrm{~cm})$.

In March 2011 the Apapa area (black box in Fig. 1) was intensively surveyed with a multibeam echo sounder (type: R2Sonic 2024 multibeam), operating at $400 \mathrm{kHz}$. Fig. 2a shows the detailed bathymetry in that area. The detailed bathymetry around the Apapa area is complex. Close to the Apapa quay walls the navigation channel is situated. Bottom elevations along this channel reveal bed forms and other natural variations, which indicates that maintenance dredging is limited or even absent. The centre of the area is relatively shallow ( $5 \mathrm{~m}-7 \mathrm{~m}$ below Chart Datum) and consists of several longitudinal bars. These bars are regarded to be part of former depositions (remnants) as they appear to be more resistant against current erosion than the surrounding area. Also steep slopes are present in the area. As sandy material is only stable for milder slopes, this indicates that cohesive sediment is also present in the bed.

The bathymetry near the Apapa area was measured during both campaigns, which made it possible to compare between bed levels in September 2010 and March 2011. This results in bed level changes in 
a this specific half year. As the single-beam sounder only produces bathymetry lines (no area), the comparison is carried out along those lines. For this analysis the highest frequency $(210 \mathrm{kHz})$ of the single-beam sounder is used.

Fig. 3 shows the bed level changes within that specific half year. Changes in the order of $10-20 \mathrm{~cm}$ are considered to be uncertainty in the measurement / comparison method. However at some locations a larger bed level difference is shown within this half year. For example, line nr. 1 shows clear erosion in the deeper navigational channel and line nr. 7 shows erosion of a part of the slope. From results of all lines (left panel) it is observed that no clear sedimentation in the deeper parts is observed within that period. From this data there is no indication that deeper parts in the Apapa channel will be filled up with sediment. This is an important conclusion, as this might also be the case after channel deepening.
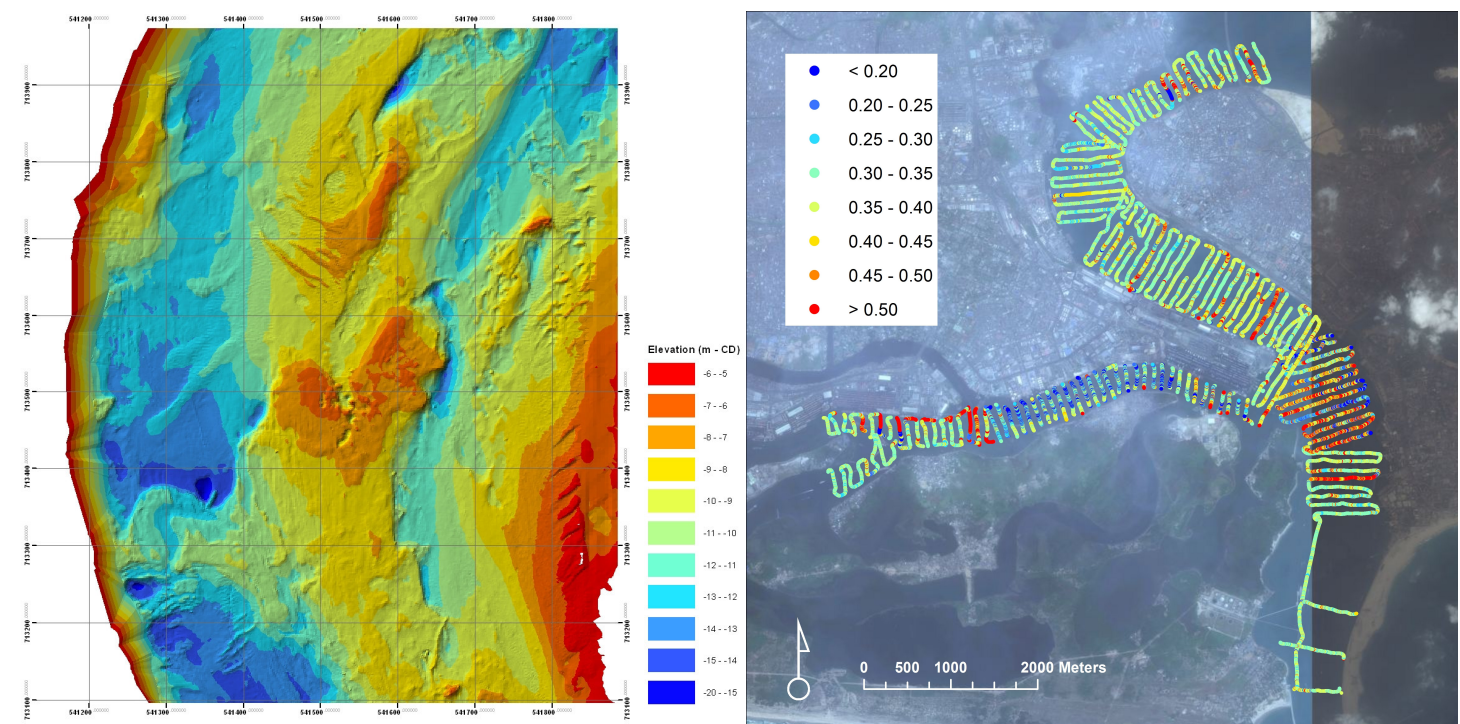

Figure 2. (left panel, 2a) Detailed bathymetry of the Apapa Area, surveyed with a multibeam echo sounder. (right panel, 2b) Indicative thickness $(\mathrm{m})$ of soft mud layer (difference between higher and lower echosounder frequency).
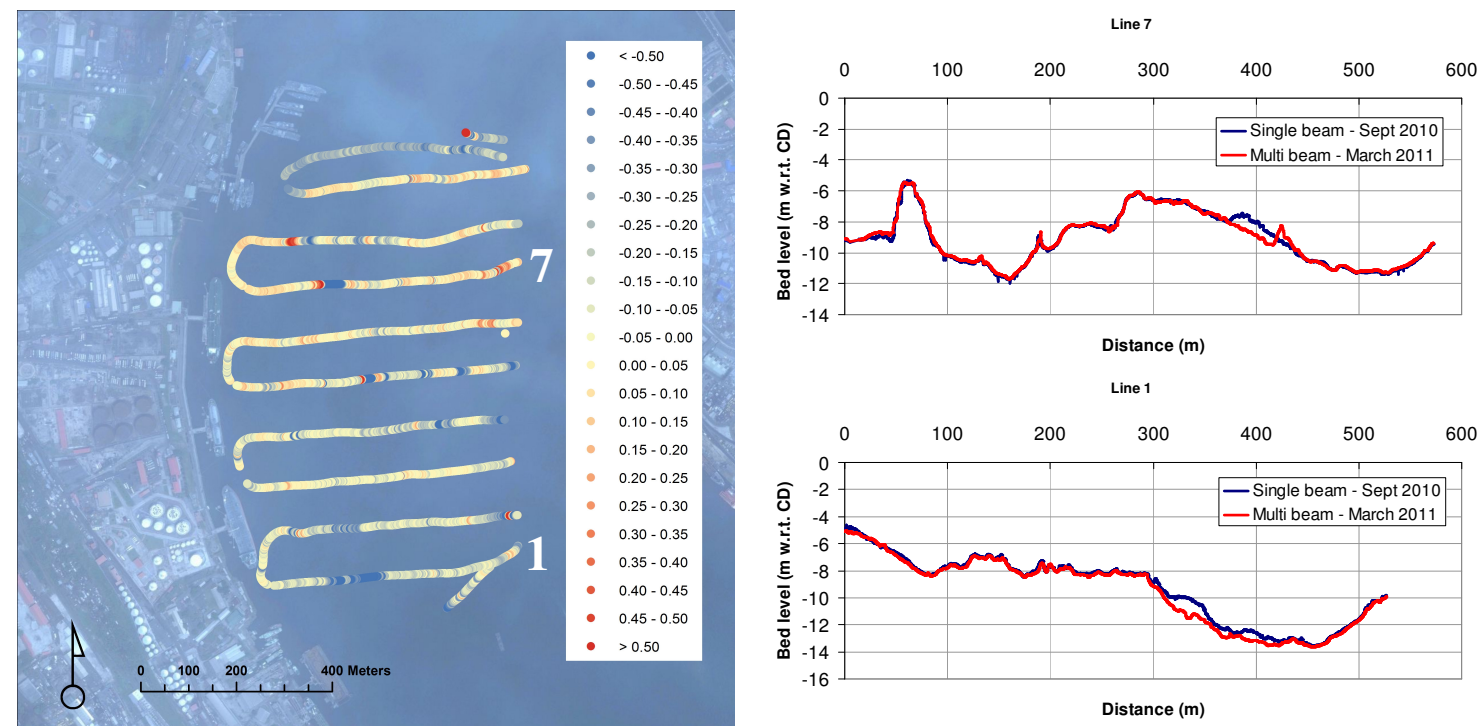

Figure 3. Bed level differences (m) between Sept. 2010 and March 2011. Left panel (3a) 2D overview (in red sedimentation, in blue erosion). Right panel (3b) shows line nrs. 1 and 7. 


\section{Water levels}

Tides at the ocean around Lagos are semi-diurnal and a periodicity of about $12 \mathrm{~h} 25 \mathrm{~min}$ but with significant diurnal inequalities (Egberangbe, 1989). The mean tidal range is approximately $1 \mathrm{~m}$, increasing to $1.5 \mathrm{~m}$ during more extreme spring tides.

Water level measurements inside the port were performed in May 2008 at the Atlas Cove Jetty (Commodore Channel), Navgas Jetty (Badagry Creek) and Five Cowrie Creek.

Another set of water level measurements was collected around April 2011. Water level information was gathered at the existing NNPC oil jetties (Apapa Channel), Atlas Cove Jetty (Commodore Channel) and Sea School (Badagry Creek). All measurements were carried out with a pressure log (type: Seabed Orinoco Solo V2, pressure sensor).

Table 1 provides tide table information inside Lagos Harbour. Furthermore, Fig. 7a and b show a part of the water levels measurements from Commorodore Channel and Five Cowrie Creek respectively.

\begin{tabular}{|c|c|c|}
\hline \multicolumn{2}{|c|}{ Water level } & \multirow{2}{*}{ Level $[\mathrm{m},+\mathrm{CD}]$} \\
\hline MHWS & Mean High Water Spring & \\
\hline MHWN & Mean High Water Neap & 0.70 \\
\hline MSL & Mean Sea Level & 0.45 \\
\hline MLWN & Mean Low Water Neap & 0.21 \\
\hline MLWS & Mean Low Water Spring & 0.09 \\
\hline
\end{tabular}

\section{Flow velocity and discharge}

Flow velocity and discharge variations are measured during field campaigns in 2008 and 2011 (dry season periods). During the field campaigns, data was gathered by using a vessel-mounted ADCP sensor (Acoustic Doppler Current Profiler, type: Teledyne RDI Workhorse Monitor $1200 \mathrm{kHz}$ ). The ADCP collects current speed information (magnitude and direction) over water depth within a fixed depth-interval. The discharge is calculated by the ADCP's data acquisition software by integrating the obtained current depth-profiles over the channel cross-section.

Fig. 7c shows measured discharges through the Commodore Channel in May 2008. Table 2 provides a discharge distribution over the several channels and creeks. As observed, approximately $25 \%$ of the total incoming discharge flows trough the Badagry creek, $4 \%$ to the Five Cowrie Creek and the remnant trough Apapa channel. Maximum in- and outflow is 9,000-11,000 $\mathrm{m}^{3} / \mathrm{s}$, which enters the system via the Commodore Channel.

\begin{tabular}{|l|l|l|l|l|}
\hline \multicolumn{5}{|l|}{ Table 2. In- and outflow measurements at several channels and creeks } \\
\hline Location & $\begin{array}{l}\text { Flow velocity } \\
\text { (m/s), inflow }\end{array}$ & $\begin{array}{l}\text { Measurement } \\
\left(\mathbf{m}^{3} / \mathbf{s}\right), \text { inflow }\end{array}$ & $\begin{array}{l}\text { Flow velocity } \\
(\mathbf{m} / \mathbf{s}), \text { outflow }\end{array}$ & $\begin{array}{l}\text { Measurement } \\
\left(\mathbf{m}^{3} / \mathbf{s}\right), \text { outflow }\end{array}$ \\
\hline Commodore entrance & 1.17 & 10,700 & 1.09 & 9,200 \\
Badagry Creek & 0.79 & 2,700 & 0.59 & 2,800 \\
Apapa channel & 0.86 & 6,900 & 0.81 & 6,000 \\
Five Cowrie & 0.21 & 400 & 0.19 & 400 \\
\hline
\end{tabular}

Fig. 7d shows corresponding flow velocities from the ADCP measurements in the Commodore Channel. Table 2 provides indicative flow velocities for several channels and creeks. Observed values in the Commodore channel are in the order of $1-1.2 \mathrm{~m} / \mathrm{s}$. These values correspond quite well with calculations of the equilibrium flow velocity in the Commodore channel by Van Bentum (2012). Equilibrium flow velocities, defined as the velocity for which the cross section of the channel is in equilibrium, were calculated at $1.2-1.3 \mathrm{~m} / \mathrm{s}$, based on tidal prisms (P, between $\left.140-200 \mathrm{Mm}^{3}\right)$ and equilibrium cross-sectional areas $\left(\mathrm{A}_{\mathrm{e}}\right.$ between $\left.8,000-11,000 \mathrm{~m}^{2}\right)$. This would indicate that the inlet is in approximate dynamic equilibrium and that therefore approx. equal volumes of sediment enter and leave the Commodore Channel during the flood respectively ebb tides (Van Bentum, 2012). If this is the case, this means that limited sedimentation will occur in the Commodore Channel. 


\section{Turbidity / Sediment concentration}

Turbidity (NTU) has been measured at several locations and during two periods:

1. At location Commodore in September 2010. Seven OBS sensors (Type: Seapoint Turbidity Meter) have been placed at several heights above the bed $(0.25 \mathrm{~m}, 0.5 \mathrm{~m}, 1 \mathrm{~m}, 2 \mathrm{~m}, 4 \mathrm{~m}, 8 \mathrm{~m}, 12 \mathrm{~m})$;

2. In March 2011 at three locations one OBS sensor was installed $1 \mathrm{~m}$ above the bed. Those locations were: Atlas Cove Jetty (near Commodore), Yacht Club and Oando Jetty. Continuous measurements are carried out from March 23 to April 4, 2011.

In the 2010 campaign, the OBS sensors have been calibrated using collected sediment samples (Ballendux, 2011). A linear relation has been found between turbidity values and sediment concentration.

Fig. 4 shows the results of the sediment concentration measurements in 2010. The concentration higher in the water column ( $2 \mathrm{~m}$ above the bed or above) is relatively stable; values in the order of 100 $-500 \mathrm{mg} / \mathrm{l}$ are observed at all days and no clear link with the tidal cycle can be found. This is totally different in the lower part of the water column. Especially the sensor $0.5 \mathrm{~m}$ above the bed shows large fluctuations, depending on the tidal movement. During maximum flood flow, corresponding with high water (no phase difference between water level and flow), the concentration increases strongly. Values are observed from $1-1.5 \mathrm{~g} / \mathrm{l}$ at the beginning of the flood period to $3-3.5 \mathrm{~g} / \mathrm{l}$ at high water. After the peak of high water the concentration drops to values of several $100 \mathrm{mg} / \mathrm{l}$. This cycle is measured at the $8^{\text {th }}, 9^{\text {th }}$ and $10^{\text {th }}$ of September 2010 and mainly at $0.5 \mathrm{~m}$ above the bed (Fig. $4 \mathrm{c}$, blue line). The sensors $0.25 \mathrm{~m}$ and $1 \mathrm{~m}$ above the bed do not show large fluctuations. As it is physically not possible that the lower sensor can give lower concentration values, we anticipate that the results of this sensor are not correct. Possibly, this sensor was (partly) placed inside the muddy bed.
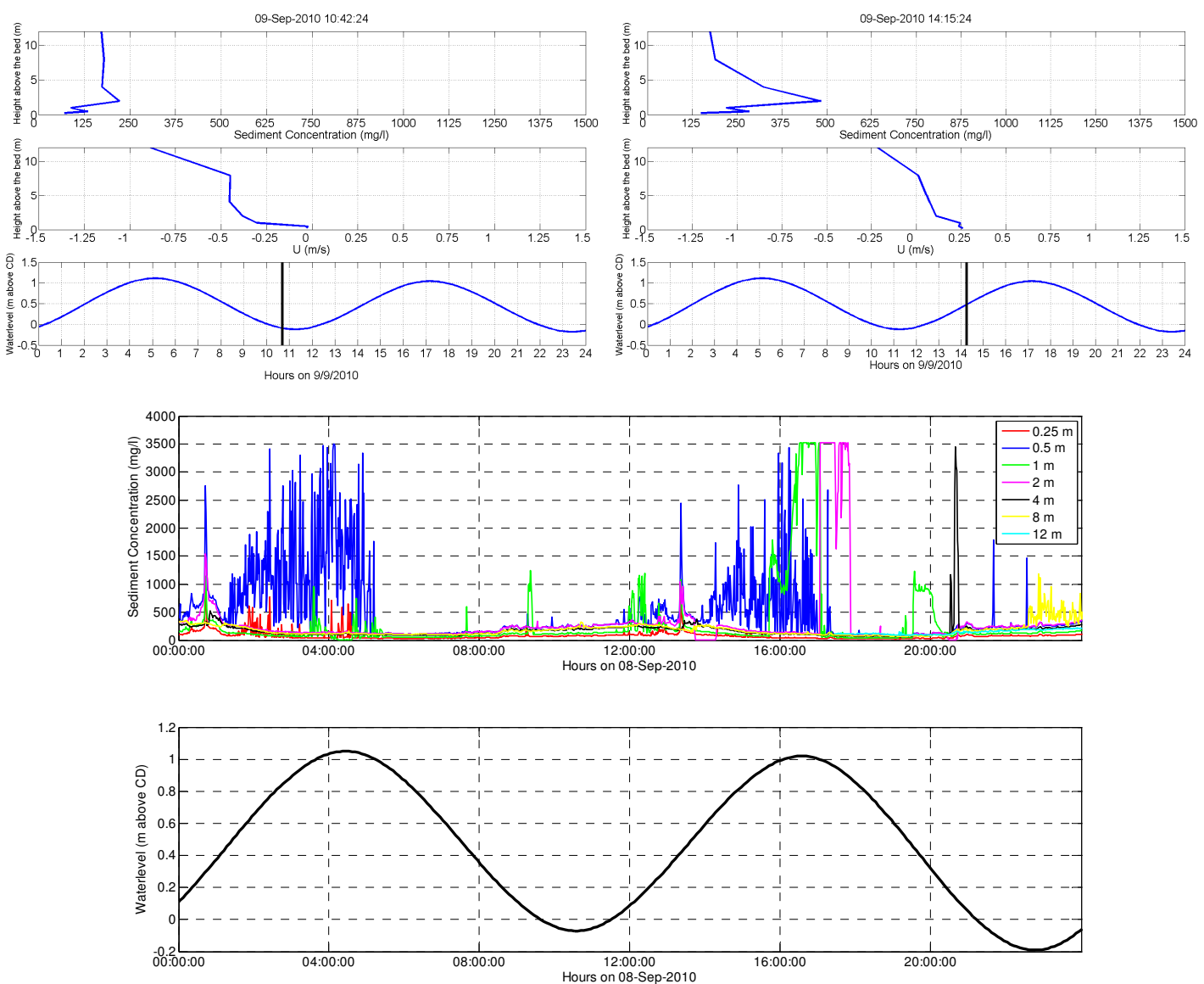

Figure 4. Upper left panel (4a) shows sediment concentration and flow velocity during ebb flow (Sept. 9, 2010 10:42). Upper right panel (4b) during flood flow (Sept. 9, 2010 14:14). Lower panel (4c) shows sediment concentration and water levels during Sept. 8, 2010 for all 7 sensors.

This behaviour in suspended sediment concentration might indicate that a high concentration layer (about $0.5 \mathrm{~m}$ thick) is transported with the tidal movement into the Commodore channel from the Atlantic. Fig. 4a and $4 \mathrm{~b}$ also explain this behaviour. In those figures, the concentration (upper panel) is 
plotted together with the flow velocity (middle panel) and moment in the tidal cycle (black line in lower panel). During ebb (Fig. 4a) the flow is negative (outflow) over the whole water column. The concentration is almost uniform around $200 \mathrm{mg} / \mathrm{l}$. During flood flow (Fig. 4b) the upper part of the water column still shows an outflow, whereas near the bed the water flows in. The concentration near the bed increases, and a non uniform profile is shown. This behaviour indicates that density effects (driven by salinity differences) play a role in the sediment transport. The influence of salinity on the sediment transport is explained in the next section, where salinity profiles are presented for the same moments as the measurements in Fig. 4.

At locations more inland in the Commodore channel the high concentration layer is not recorded by the OBS sensor in 2011. However, there are indications that this layer is present at these locations as well. The OBS sensor at the location of Apapa showed slightly higher concentrations during maximum flow period. This indicates that at this location mixing of the sediment layer in the water column occurs at that time. The dual frequency echo sounder measurements show a soft mud layer of $20-30 \mathrm{~cm}$ at the Apapa location. Mixing from this layer will probably occur during maximum flow.

\section{Salinity}

The combined discharge of saline tidal water and fresh rainfall runoff may cause stratification of the water column; where relative low-density fresh rain water "flows" on top of saline tidal water. A stratified water column may have impact on fine sediment transport. Due to density effects, additional density currents can be generated, which can transport fine material into the port area. For this reason it is important to investigate if stratification occurs at the location of channel deepening. Salinity depthprofiles were measured with a YSI-sensor (type: Castaway) in September 2010 at three locations within Lagos Harbour (Commodore, Apapa and Badagry) and in March 2011 only at the Apapa area. In September 2010 limited salinity data was collected, only a few profiles per day for each location. In March 2011 many profiles were measured during almost one complete week. Fig. 5 shows the results of the 2010 measurements.

At location Commodore (in the harbour entrance), salinity fluctuates between $10 \%$ and $34 \%$, depending on the tide and fresh water discharge. Less stratified profiles were measured (Fig. 5a) at 7:55 and 10:42, whereas strong stratification occurs during flood at 14:14.

At the location Badagry, even higher stratification is measured. Near the bed salinity values of $34 \%$ were measured. Near the water surface, $7-8 \%$ is found (Fig 5c).

Measurements at the Apapa location (Fig. 5b) do not show strong stratification. Only a thin layer of less saline water (21\%o) is found on top of more saline water $(33 \%)$ around $7-9 \mathrm{am}$. At 11:00 am a uniform profile is measured with a salinity of approximately $16 \%$. This corresponds with ebb flow.

During the measurement campaign in March 2011 strong stratification is also not observed at the Apapa location and values correspond to the 2010 measurements. All salinity values are in the range between $24 \%$ (measured at the end of the ebb flow) and 34\%o (measured at the end of the flood flow), hence density currents are still to be expected.

With regards to fine sediment transport, it is useful to determine if stratification is stable and under which conditions. To asses the stability of stratification, the Richardson number is computed for several conditions, based on the field measurements. The gradient Richardson number can be defined as (Winterwerp, et al, 2004),

$$
R i=-\frac{g \partial \rho / \partial z}{\rho(\partial u / \partial z)^{2}}
$$

Where $\mathrm{g}$ is the gravitational acceleration $\left(9.81 \mathrm{~m} / \mathrm{s}^{2}\right)$, $\mathrm{u}$ is the flow velocity $(\mathrm{m} / \mathrm{s}), \rho$ the water density $\left(\mathrm{kg} / \mathrm{m}^{3}\right)$ and $\mathrm{z}$ the vertical coordinate $(\mathrm{m})$. Stratified flows are considered to be stable when $\mathrm{Ri}>$ 0.25 .

For location Commodore channel, this analysis is carried out, taking into account the velocity profiles from Fig. 4 and salinity profiles from Fig. 5a. The Richardson number is much larger than 0.25 for both situations. Hence, from these salinity measurements and analysis it can be concluded that stratification is stable for a certain period within the tidal cycle. This influences the fine sediment transport in the southern part of the Commodore channel. 


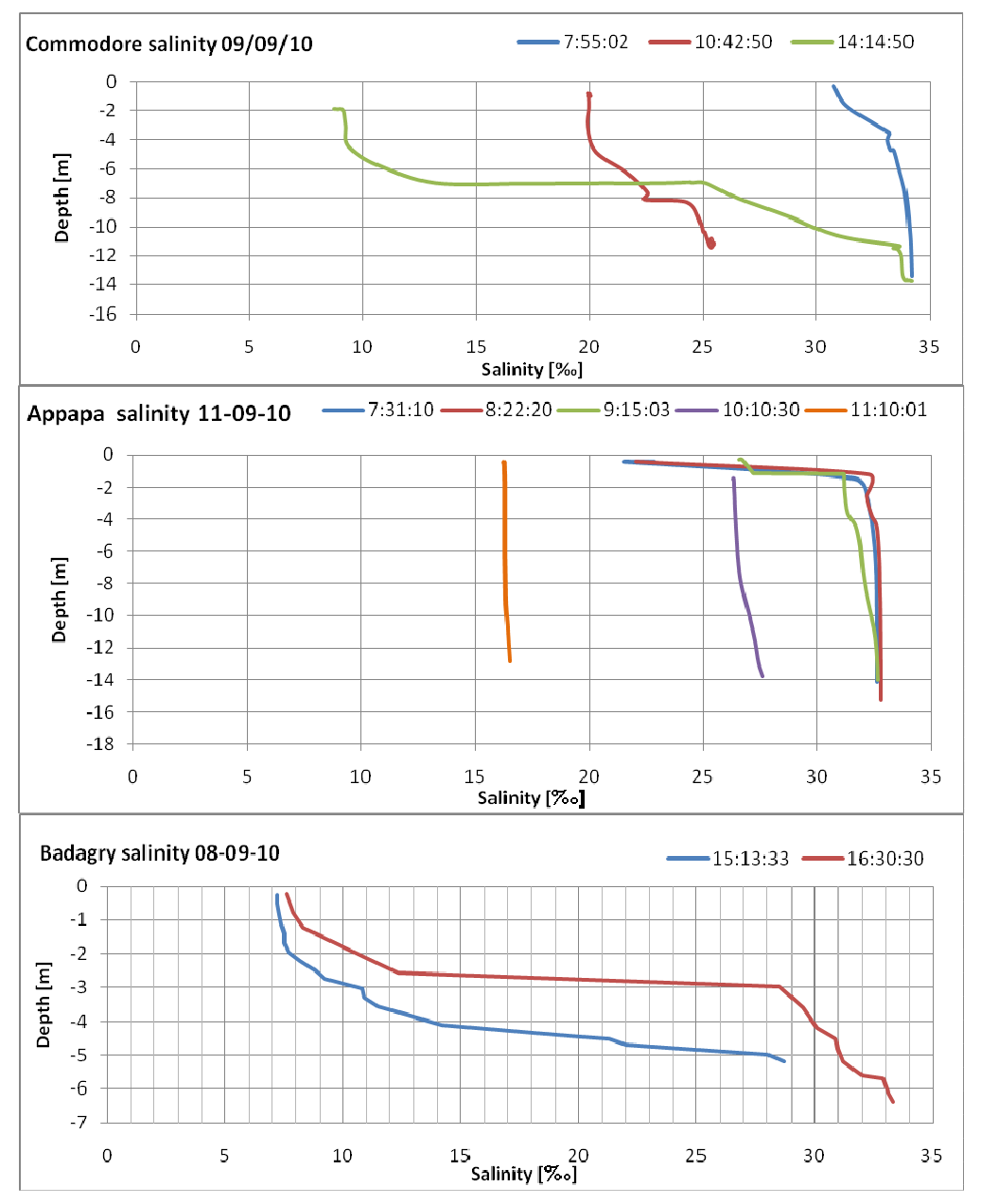

Figure 5. Salinity measurements, campaign September 2010 (Ballendux, 2011)

\section{MODEL DEVELOPMENT}

In order to derive design conditions for the marine structures and to determine the hydraulical and morphological effects of future port developments, a numerical flow model has been developed. Besides, the model is used for a qualitative analysis on the morphological effects of channel dredging. This last aspect will be discussed in this paper, as well as the setup of the numerical model.

\section{Model setup}

The MIKE21 modelling package is used for this study in the form of the hydrodynamic module with flexible mesh (MIKE21-HD). MIKE21 is a modelling system based on a flexible mesh approach which has been developed for application within oceanographic, coastal and estuarine environments (DHI, 2008). 2D modeling was applied, because the effects of estuarine circulation are small in the area of interest. The location where capital dredging is needed (Apapa area) is more upstream in the main channel.

The total area covered by the model is shown in Fig. 6, as well as the locations of the model boundaries. The distance from the offshore southern boundary to the coastline is about $12 \mathrm{~km}$. The southern boundary is located offshore at a depth of $-35 \mathrm{~m}$ to have spatially constant boundary conditions. The model extent in east-west direction is about $28 \mathrm{~km}$ at sea, and inland approx. $95 \mathrm{~km}$.

The computational mesh has different levels of resolution and is composed of triangular elements. These elements allow the grid to be unstructured and to have different levels of resolution within the model. In the offshore area, large depths allow the mesh to be coarse, with node distances up to $1 \mathrm{~km}$. In the setup used for mesh generation, several transition zones are applied to smoothly connect the coarse mesh offshore with the high density mesh in the Commodore and Apapa channels. At these locations, node distances are some 20 meters apart. Within the harbour inlet, creeks and lagoons, the element size in the inland water system varies in order to have enough resolution in each cross-section 
to model the flow patterns correctly. Around the moles the element size is about 50 meter. In the inlet the element size ranges between 25 to 50 meters.

The bathymetry model (DTM) of Lagos Harbour has been set-up based on a combination of several data sources, such as bathymetry measurements (2008, 2010 and 2011), GEBCO (General Bathymetric Chart of the Oceans) data, MIKE C-map data and Admiralty Charts. Fig. 1 shows a part of the final model bathymetry.

Six different types of boundaries are defined (Fig. 6). The south boundary is set to a closed boundary with zero normal velocity. The land boundary is also a closed boundary with zero velocity (white lines). The boundaries in Lagos Lagoon and the lake at Magbon are river discharge boundaries. For simulations representing the wet season, a river run-off discharge is imposed along these boundaries.

Table 3 provides discharge information for the two river boundaries for two different return periods. Discharge values were based on rough rainfall run-off computations.

\begin{tabular}{|l|l|l|}
\hline \multicolumn{3}{|c|}{ Table 3. Discharge boundary conditions for two return periods. } \\
\hline Return Period & Boundary & Discharge \\
\hline $1 / 100$ year & River boundary west & $1,880 \mathrm{~m}^{3} / \mathrm{s}$ \\
& River boundary east & $8,480 \mathrm{~m}^{3} / \mathrm{s}$ \\
$1 / 1$ year & River boundary west & $940 \mathrm{~m}^{3} / \mathrm{s}$ \\
& River boundary east & $4,240 \mathrm{~m}^{3} / \mathrm{s}$ \\
\hline
\end{tabular}

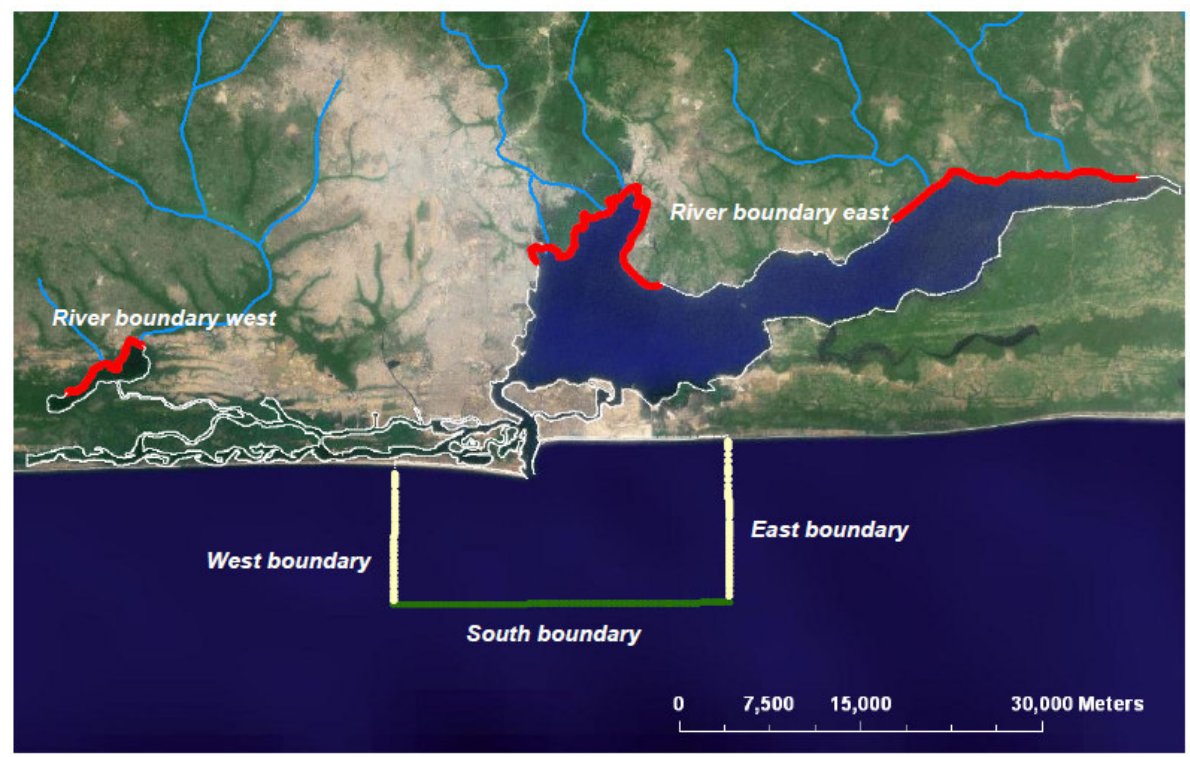

Figure 6. MIKE 21 model area and location of the boundaries

The open ocean boundaries at the east and west are set to water level boundaries varying in time and along the boundary. The water level boundaries are extracted from the global tide model by DHI. The global tide model data represents the major diurnal (K1, O1, P1 and Q1) and semidiurnal tidal constituents (M2, S2, N2 and K2) with a spatial resolution of $0.25^{\circ} \times 0.25^{\circ}$ based on TOPEX/POSEIDON altimetry data. The extracted data from the global tide model is a line series data file, which contains time series of water levels along the specified boundary line. The water level variation at the boundaries is extracted for the relevant simulation periods in 2008, 2010 and 2011, for which calibration and validation data was available from the field measurements.

\section{Calibration / Validation}

The calibration of the model is based on the data provided by the measurement campaign from the $3^{\text {rd }}$ till the $9^{\text {th }}$ of May 2008. The simulation period used for calibration is 5-3-2008 15:00 until 5-6-2008 15:30. As this is still the dry season, zero river discharge is set on the two river boundaries.

The critical issue for the flow model is to model the tidal volume through the inlet correctly. The incoming tidal volume is limited by the storage capacity of the inland lagoons and the roughness and width of the channels. To model the storage capacity correctly, it was chosen to include a large area of the Lagoon and a large area to the west connected to Badagry Creek. By changing the bed resistance, 
the model was tuned to calculate the right flow volume distribution of water through the various channels and creeks. The bed resistance has been used as the major factor to modify this fine-tuning (calibration) process.

The calibration results mainly focus on the discharge distribution over the various channels. Secondly, the prediction of measured water levels and currents in the area in and around the Commodore channel are checked against measurements.
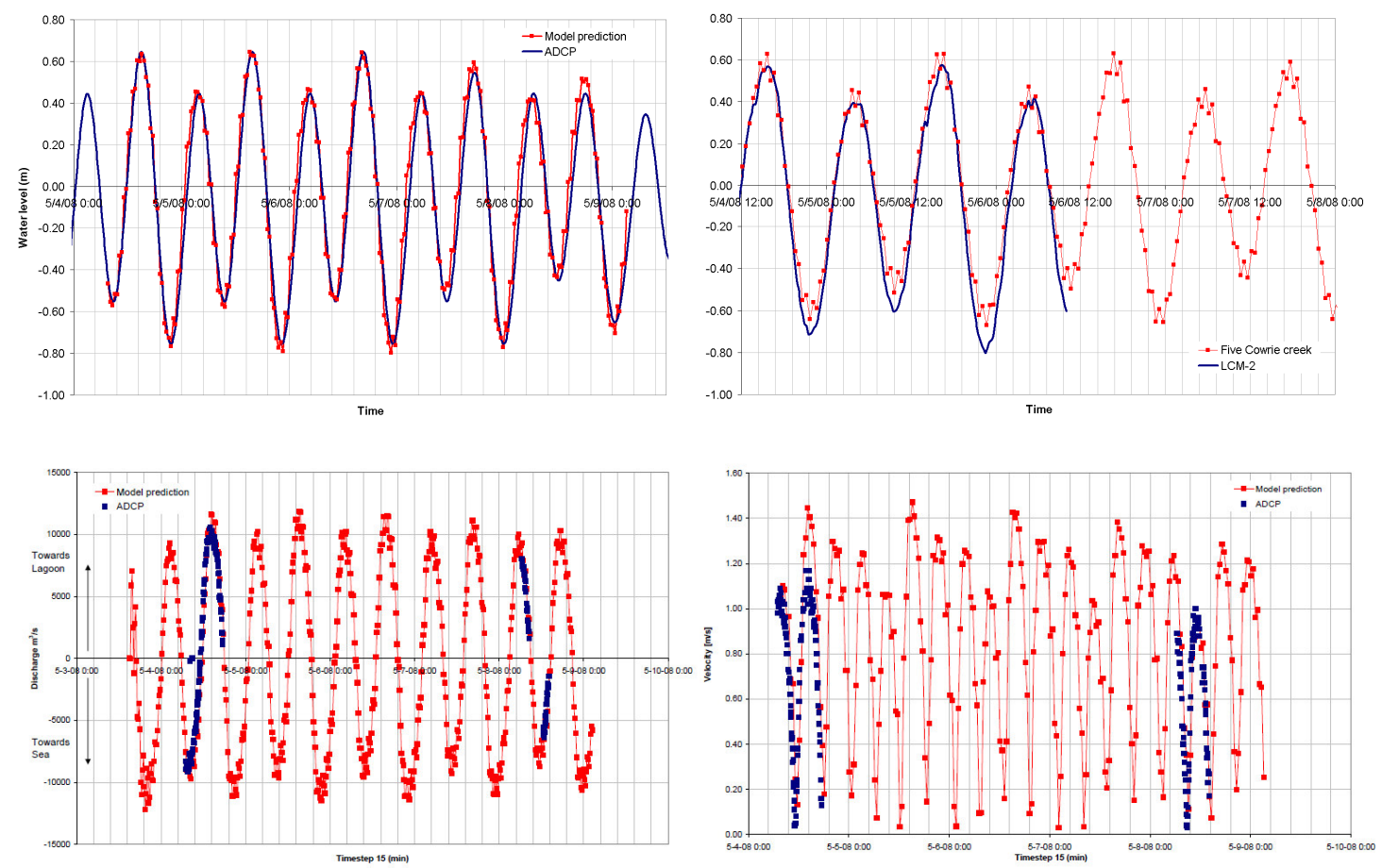

Figure 7. Results of the calibration of the model. Upperleft panel (7a) water levels at location Commodore channel. Upper right panel (7b), water levels at Five Cowrie Creek. Lower left panel (7c) Discharge trough Commodore channel and lower right (7d) corresponding flow velocities. In red, model prediction. In blue measurements.

Fig. 7c shows the results for the tidal volume flowing in and out through the inlet. The blue line presents the recordings of the measurement campaign; the red line presents the model results. The model prediction for in and outgoing tide are in compliance with the ADCP measurements for the 2008 data. Discharges in the range of $10,000 \mathrm{~m}^{3} / \mathrm{s}$ are recorded in the Commodore channel.

Fig. 7a shows the results for the water level variation during a tidal cycle at the Commodore channel entrance for both the model and the available ADCP measurements. The model predicts the water level at the Commodore entrance accurately. Water levels in the Five Cowrie Creek (Fig. 7b) are compared to the available LCM data (Lagos Channel Management). Again, the model predicts the water levels accurately; a slight over estimation of incoming tide can be seen as well as a minor underprediction of outgoing tide.

Fig. $7 \mathrm{~d}$ shows the results for current speed at the inlet. The red line presents the recorded average current speed over the cross-section of the inlet; the blue line presents the model results over the same cross-section. It appears that the maximum current speed during inflow at the inlet is overestimated by $25 \%$ and during outflow the model prediction is accurate.

For the validation event, ADCP and water level measurements are used for the period of 25 March 2011 8:34 AM until 4 April 2011 15:42 PM. The calibrated model was run for this period to compare model results with measurements. For the 2011 measurements, only the Oando Jetty location was considered, as this is located in the area of interest.

Validation results, shown in Fig. 8, are not as good as the calibration results. Tidal water levels were underpredicted by 15 to $20 \%$ and discharges were overestimated by $15 \%$. As it is anticipated that the discharge measurements were not taken correctly, this results seems to be quite reasonable. The under prediction of the discharge is also shown in the current velocity results. Velocities were predicted within 10 to $20 \%$ accuracy, but the model shows an overestimation. 

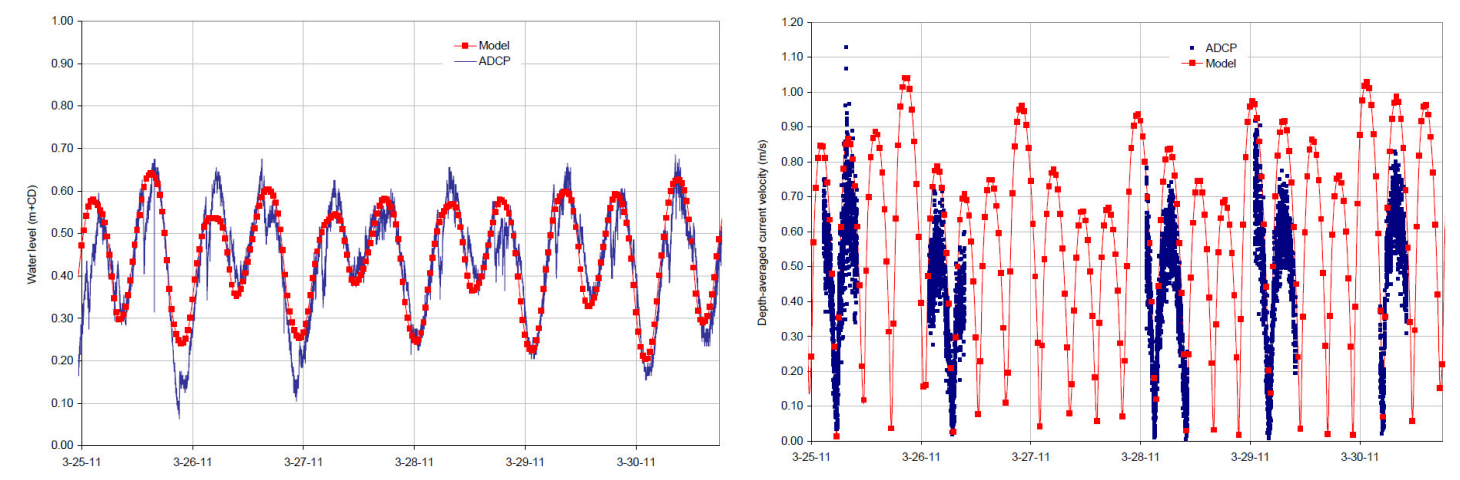

Figure 8. Results of the validation of the model. Left panel (8a) shows water levels near Apapa, right panel (8b) flow velocity at the same location. In red model predictions, in blue measurements.

In the end, the calibration / validation process has resulted in an acceptable prediction of the discharge distribution over the various creeks and channels during the tidal cycle. The model is suitable to simulate the effects of channel deepening. As the effects of port developments will be determined relative to the present situation, systematic model inaccuracy of the present situation will be distracted from the future situation, and therefore of minor importance.

\section{Effects of dredging}

To determine if dredging in the Apapa area causes an increase of sedimentation and, as a result, an increase in maintenance dredging, the model was used to evaluate the morphological effects. The effects of channel deepening were determined based on changes in bed shear stresses. Four output locations inside the deepened area were defined, to compare bed shear stresses during the spring-neap cycle. In total 8 model runs were carried out with varying fresh water discharge and bed roughness, to analyze the effects for several conditions and to determine the sensitivity of the model outcomes for different physical parameters.

The model simulations show a variety in bed shear stresses at the location of the proposed deepening around the Jetty (Fig. 9). This variety depends on several factors. Larger flow velocities, due to tide or increased by fresh water discharge, show larger shear stresses. In case higher roughness values are applied, this results in larger shear stresses as well.

After channel deepening, bed shear stresses are expected to drop with approximately $30-40 \%$, depending on the location. However, the model simulations also show that the bed shear stress will often exceed values of $0.5-1 \mathrm{~N} / \mathrm{m}^{2}$. This is especially the case for simulations including fresh water discharge.

Ballendux (2011) showed that the mud in the Commodore and Apapa area mainly contains montmorillonite clays. Critical shear stresses of these type of sediments can be derived from Torfs (1995) and exceed $1 \mathrm{~Pa}$ only at very high mud/clay content. However, these larger critical bed shear stresses will be measured only after many days of consolidation. Therefore, we do not expect critical bed shear stresses beyond $0.5-1 \mathrm{~Pa}$ in our case. This is further sustained by the fact that at the 4 output locations, where computed minimal bed shear stresses amount to about $0.5 \mathrm{~Pa}$, no mud accumulation is observed from our measurements (Fig. 3). Furthermore, sediment samples, taken in the area, only show sandy material at the bed (Ballendux, 2011).

So, observations show that no mud accumulation occurs at bed shear stresses computed around 0.5 $\mathrm{Pa}$. Simulations show that such bed shear stresses are exceeded most of the time after deepening around the Jetty location (shear stresses of $0.5-1 \mathrm{~Pa}$ will be exceeded often during normal hydraulic conditions.). Therefore, fluid mud layers, which can flow into the deeper part, will not be able to consolidate as these locations and will be stirred up from time to time. As a result, no high mud siltation rates are expected in the deepened parts of the river along Apapa channel. Sedimentation inside the dredged parts, if occur, will originates from migration of sandy bed forms. Indicative sand transport simulations (MIKE21-ST) show that large sedimentation rates can occur due to transport of sand into the deepened area. However, due to the absence of proper calibration data (sediment transport) for the same period, it is questionable if this morphological model is reliable at the moment. Further morphological model development is needed, to improve the understanding of the morphodynamics in the system. For the time being, monitoring should be carried out to check if large sedimentation rate occur inside the deepened channels. 

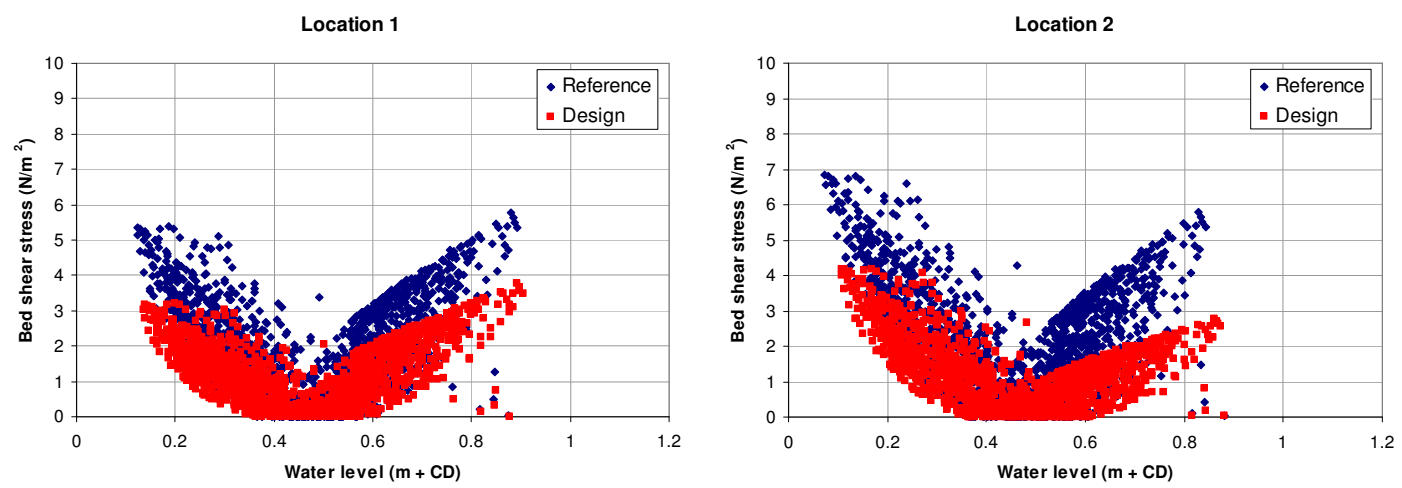

Location 1
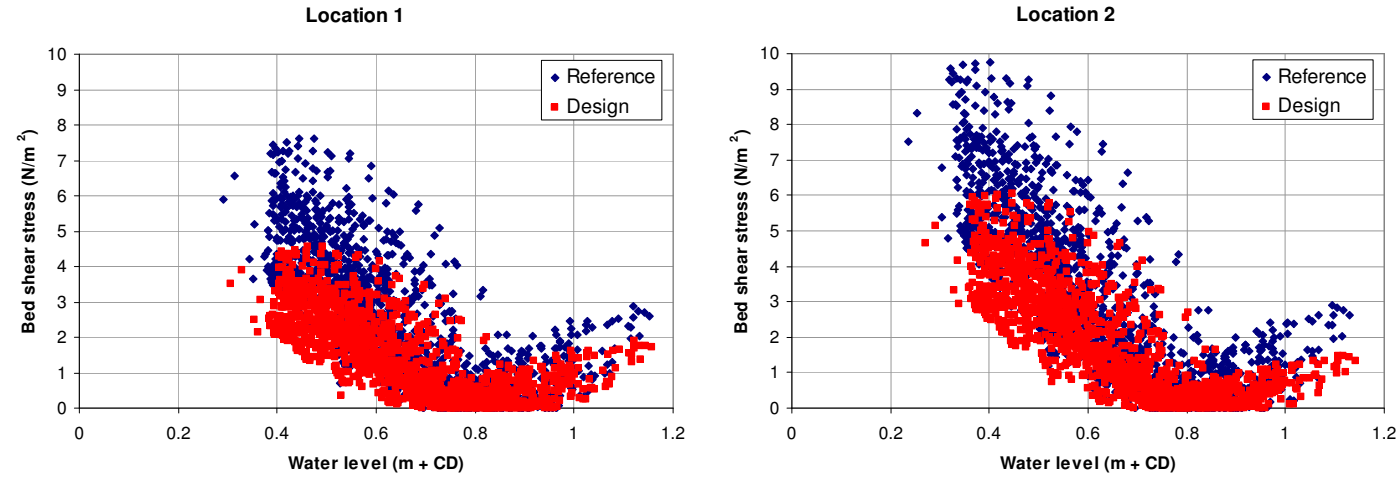

Figure 9. Bed shear stresses computed by the model at two locations inside the dredged area. In blue the shear stresses without dredging, in red the situation included the dredging. The upper panels show results for the computations without fresh water discharge. The lower panels show results of the simulation including a 1/year fresh water discharge.

\section{CONCLUSIONS}

During the 2010 measurement campaign, pronounced density currents were observed in Commodore and Badagry channel. In these channels, strong stratification has been observed with lowsaline water near the surface and salt water near the bed. Just after low water slack, large turbidity values and an inflow of water were measured near the bed while higher in the water column outflow is still observed. This results in net up-estuary near-bed transport of courser material from the ocean and net ebb transport of finer material in the upper part of the water column. Near Apapa, such estuarine circulation is not observed.

Although dual frequency echo sounder measurements suggest the existence of a layer of soft material across the whole system, only sandy material was found in the bottom samples of the Commodore and Apapa channel. This is explained from the high flow velocities inside the main channel. From other studies (Bakker, 2009 and Ballendux, 2010) we anticipate that the fine material consists of poorly flocculated sediment (montorillonite clay), which would explain the absence of fine sediment on the bed. The response of the dual-frequency echo-soundings is therefore not understood, and should be studied further. However, bottom samples taken in Badagry creek do contain fine material, indicating that in this creek, conditions are suitable for fines to settle. Therefore, heavy siltation is observed along the quay walls of Badargy creek and dredging activities are mainly observed in this area of the port.

A 2D hydrodynamic model (MIKE21, flexible mesh) of the Lagos Harbour and its lagoon was build to evaluate the effects of local channel deepening near Apapa. As the effects of estuarine circulation are small in the area of interest (which is more upstream in the main channel), 2D modeling can be applied. The model was successfully calibrated and validated with the field data from three measurement periods.

Model simulations for different scenarios show that bed shear stresses are large, also inside the deepened channel. Fluid mud layers are not expected to accumulate and consolidate, as these layers must be stirred up frequently, when hydraulic forcing exceeds critical values. Therefore, no 
pronounced siltation of mud is expected. Sand transport, however, may cause sedimentation, requiring maintenance dredging. These model results are in line with interpretations from the field data. First order sediment transport simulations show large bed level changes inside and close to the deepened channels. Such large changes are also observed from comparing bed level data of 2010 and 2011, resulting from profound migrations of bed forms, the latter visible on the multi-beam records.

To understand these large siltation rates, further morphological studies are needed, in combination with specific field measurements (including seasonal effects), to better understand the sediment transport processes.

\section{ACKNOWLEDGMENTS}

The authors want to thank Bas van de Sande for his assistance in producing the GIS figures. We also want to thank the MSc graduation students Vincent Ballendux and Karen van Benthum from Delft University of Technology and Royal Haskoning, for sharing their knowledge about the Lagos Area.

\section{REFERENCES}

Bakker, S.A. 2009. Uncertainty analysis of the mud infill prediction of the Olokola LNG terminal, MSC Thesis, Delft University of Technology.

Ballendux, V. 2011. On the Morphodynamics of Lagos Harbour: an exploratory study of the tidal system, MSc Thesis, Delft University of Technology.

Bentum, K.M. van. 2012. The Lagos coast - Investigation of the long-term morphological impact of the Eko Atlantic City project, MSc Thesis, Delft University of Technology.

Cares 2010. New oil products jetty in Lagos harbour - Dredging feasibility study. Document ref. C9344-1556, may 2010.

DEEP 2011. Bathymetric, object detection, hydrodynamic and sediment concentration survey - Oando Jetty project, Lagos. Document number: P2231_SIS_R00.

DHI 2008. Mike 21 flow model FM - Hydrodynamic and transport module, scientific documentation.

Ibe, A.C.; Inegbedion, L.E.; Egberongbe, F.A.O.; Orupabo, S. (1989), Online beach evolution model for Nigerian shoreline: a case study of Victoria bar beach, Lagos.

Nkwoji, J. A., Yakub A., Ajani, G. E., Balogun, K. J., Renner, K.O., Igbo, J. K., Ariyo, A. A., Bello, B. O. 2010. Seasonal Variations in the Water Chemistry and Benthic Macroinvertebrates of a South Western Lagoon, Lagos, Nigeria. Journal of American Science, 2010;6(3).

Royal Haskoning 2011. Oando Jetty design conditions, Lagos Nigeria.

Torfs, H. 1995. Erosion of sand/mud mixtures. PhD Thesis, Katholieke Universiteit Leuven.

Winterwerp, J.C., and Van Kesteren, W.G.M. 2004. Introduction to the physics of cohesive sediments in the marine environment. 1st edition. Elsevier. 